\title{
NATURALLY OCCURRING SUBSTANCES AND THEIR ROLE IN CHEMO-PROTECTIVE EFFECTS
}

\author{
Miroslava Bilecová-Rabajdová1, Anna Birková1, Peter Urban¹, Kristína Gregová2, Eva Ďurovcová3, \\ Mária Mareková \\ 1Department of Medical and Clinical Biochemistry and LABMED a.s., Faculty of Medicine, Pavol Jozef Šafárik University, Košice, Slovakia \\ 2Department of Histology and Embryology, Faculty of Medicine, Pavol Jozef Šafárik University, Košice, Slovakia \\ ${ }^{3}$ Laboratory diagnostic LABMED, Košice, Slovakia
}

\begin{abstract}
SUMMARY
Cancer chemoprevention is defined as the use of natural, synthetic or biological chemical agents to reverse, suppress or prevent carcinogenic progression of invasive cancer. Carcinogenesis is a complex multi-step process; therefore, it is necessary to attack cell proliferation, stimulate apoptosis and inhibit angiogenesis. There have been more than 60 randomised trials using chemopreventive potential agents.

The success of several recent clinical trials in preventing cancer in high-risk populations suggests that chemoprevention is a rational and appealing strategy. In this review, we describe the conceptual basis for the chemoprevention of cancer, proven concepts of efficiency and current trends in the use of chemopreventive agents according to place and mechanism of action. We classify chemopreventive substances into seven groups based on their chemical structure and their effects, namely, deltanoids (paracalcitriol), retinoids (13-cis retinoic acid), non-steroidal anti-rheumatics (Deguelin), antiestrogens (genistein), polyphenols (curcumin), sulphur containing compounds (sulforaphane) and terpenes (lycopene). Chemoprevention is one of several promising strategies for reducing the incidence of malignant tumours or helping to prolong the time before recurrence.
\end{abstract}

Key words: chemoprevention, cancer, malignant transformation, inhibitors of metastasis

Address for correspondence: M. Mareková, Faculty of Medicine, Pavol Jozef Šafárik University in Košice, Trieda SNP 1, 04011 Košice, Slovakia. E-mail: maria.marekova@upjs.sk

\section{INTRODUCTION}

Chemoprevention is understood to mean the use of natural or synthetic substances to slow, inhibit or insult the start of carcinogenesis - the change in the genetic and regulation system of the cell induced by carcinogens. In respect to the individual phases of carcinogenesis, anti-initiating, anti-promoting and anti-progressive strategies play a role in chemoprevention. Anti-initiating strategies include scavenging DNA-reactive electrophilic compounds and free radicals, intensive carcinogen detoxification or stimulating DNA repair mechanisms. Inhibiting proliferation and angiogenesis, supporting apoptosis and scavenging ROS - reactive oxygen species represent anti-promoting and anti-progressive approaches.

Phytochemicals are substances present in fruit, vegetables and different plants, and some phytochemical have a modulation potential that is very beneficial regarding cancer chemoprevention. Naturally occurring chemopreventive compounds can be divided, according to their chemical structure and biological activity, into a few groups: terpenes, sulphides, phenols, organic acids and other macromolecules. The mechanism of phytochemical action is set on anti-oxidative effects, carcinogen detoxification through cytochrome P450 activation, carcinogen modification by inhibition of specific enzymes, regulation of gene expression during cell proliferation and apoptosis as well as modification of hormone receptors and inhibitory effects on the vascularisation of a tumour. All of the following - deltanoids, retinoids, rexinoids, antiestrogens, aromatase inhibitors, 5-alfa reductase,
COX-2 inhibitors, non-steroidal anti-inflammatory drugs, some fruits or plants substances like epigalocatechin-3-galat, curcumin, resveratrol, lycopene as well as the other antioxidants like vitamin E, N-acetylcysteine, L-carnitine and selenium - are among chemopreventives.

\section{Deltanoids}

Deltanoids are derivates of vitamin D. The active form of vitamin $\mathrm{D}$ is calcitriol (1, 25-dihydroxycholecalciferol), which is synthesised in the skin from 7-dehydrocholesterol after UV-B irradiation followed by hydroxylation in the hepatocytes and oxidation in the kidneys (Fig. 1.A). In many studies calcitriol is believed to be a chemopreventive substance with anti-proliferative, anti-angiogenic, anti-metastatic and pro-apoptotic effects (1-5). Chemopreventive and anti-carcinogenic effects are caused by binding to a specific nuclear vitamin D receptor-VDR. Activated VDR influences the transcription of many genes associated with differentiation, proliferation, neo-angiogenesis, and metastasis.

Different studies have shown this chemopreventive effect in carcinoma of the breast, prostate, bladder, and colorectum as well as in bone cancer or myelodysplastic syndrome, especially when using calcitriol and paracalcitriol (19-nor-1, 25-dihydroxyvitamin D2) (Fig. 1.B), but thus far these findings have not been supported by randomised controlled trials $(4,6,7)$. In essence, the implication resulting from the Institute of Medicine (IOM) report concerning the non-osseous roles of vitamin D is that there may be a biological plausibility and/or an epidemiological association. 


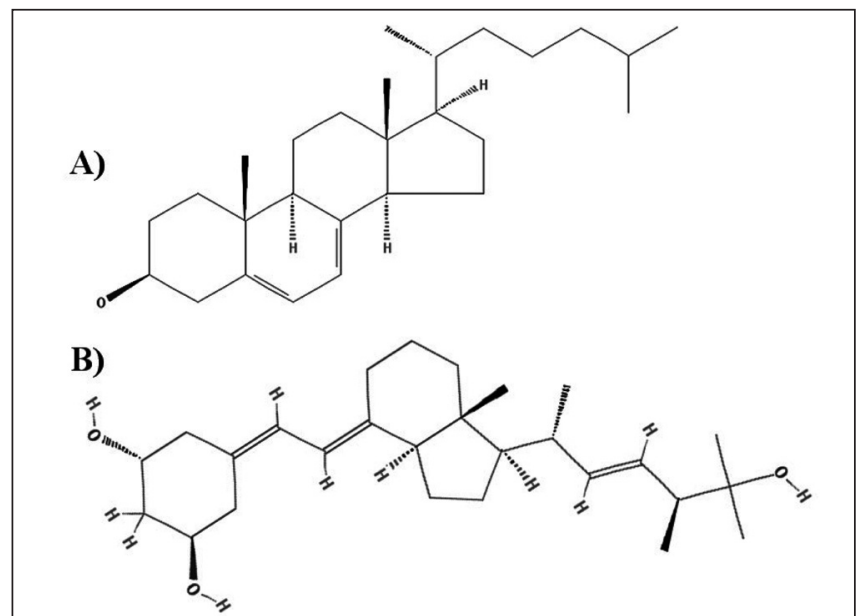

Fig.1. Deltanoids: A) 7-dehydrocholesterol, B) 19-nor-1, 25-dihydroxyvitamin $D 2$.

However, there is no consistent, conclusive or sufficient evidence to support a daily dose or a range of serum $25-(\mathrm{OH}) \mathrm{D}$ concentrations associated with the non-osseous functions of the vitamin (8).

\section{Retinoids, Rexinoids}

Natural or synthetic derivatives of retinol - vitamin A (3, 7-dimethyl-9-(2, 6, 6-trimethyl-1-cyclohexenyl)-nona-2, 4, 6, 8 -tetraen-1-ol) - are called retinoids. The main supply of naturally occurring retinoids occurs in form of retinyl esters from animal foods. Due to the activity of isomerase in cells, specific isomerase derivatives are created; these bind to specific nuclear receptors RAR (retinoid acid receptor) or RXR (retinoid X receptor). Each of them comprises three isotypes encoded by separate genes, designated $\alpha, \beta$ and $\gamma$ (9). Rexinoids are defined as agents that bind selectively to RXR receptors. In general, retinoids with a selective effect on RAR have different biological properties than rexinoids with a selective effect on RXR. Retinoid receptors are homo or heterodimeric. Once activated, retinoid receptor dimers bind to DNA at retinoic acid response elements and act as transcription factors that regulate the expression of genes which control cellular differentiation and proliferation. Retinoid agonists can activate the expression of retinoid-regulated genes by removing negative transcription control or by facilitating positive transcriptional activity. They exert anti-cancer action by interfering with the growth of tumour cells (10). Differentiation therapy of acute promyelocytic leukemia (APL) is based on the ability of retinoic acid to induce differentiation of leukemic promyelocytes. All cases of APL are associated with chromosomal translocations involving RAR $\alpha$ (retinoic acid receptor). More than $99 \%$ have a characteristic chromosomal translocation which produces a fusion protein between RAR $\alpha$ and a protein called promyelocytic leukemia protein (PML) (11). PML-RAR $\alpha$ is responsible for the initiation of leukemogenesis in humans (12).

13-cis retinoic acid (RA) was used as chemopreventive agent after bone marrow transplantation in neuroblastoma via blockade of p21, p27, cyclin E and cyclin A during the cell cycle (13) (Fig. 2). Upregulated p21 by RA accompanies caspase-3 activation and precedes the occurrence of apoptosis, p21 induction leads to increased p21 complex formation with cyclin E/CDK2, which occurs when cyclin E and CDK2 levels remain constant. CDK2

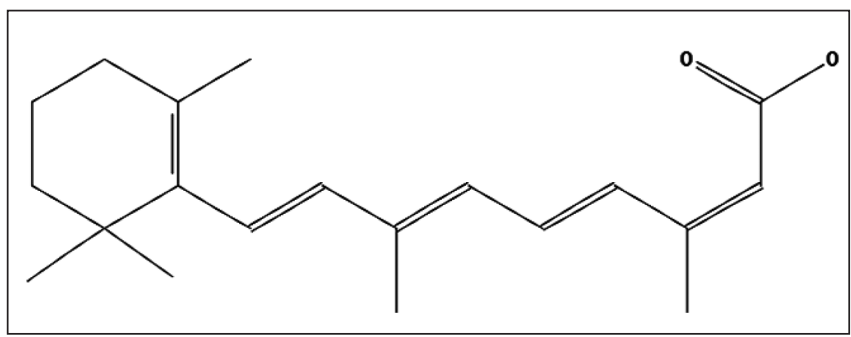

Fig. 2. Retinoids, 13-cis retinoic acid.

can alternatively promote apoptosis, but the mechanisms remain unknown. These data suggest a novel RA-signaling, by which RA-induced p21 induction and complex formation with cyclin E/ CDK2 diverts CDK2 function from normally driving proliferation to alternatively promoting apoptosis (14).

The regression of disease after targeted administration of ATRA (all-trans retinoid acid, tretinoin) has been observed. N-4hydroxyfenyl-retinamid is able to induce apoptosis in carcinoma of the breast, bladder and prostate, especially after oxygen radical injury. Bexarotene, the selective antagonist of RXR receptor, is believed to be an effective chemotherapeutic for cutaneous T-cell lymphomas. This is why RARs and RXRs expression and their role in chemoprevention and cancer therapy are among the leading topics of scientific study. In the past two decades, a number of experimental and clinical studies have been performed with retinoids showing the inhibition or reversion of the carcinogenic process in some organs, including hematological malignancy as well as premalignant and malignant lesions in the oral cavity, head and neck, breast, skin, and lung (9). Although Bettoli (15) in his review notes that despite numerous studies in the literature concerning retinoids in the chemoprevention of NMSC (nonmelanoma skin cancer), the type of retinoid, dosage and duration of preventive treatment and management of side effects in the case of long-lasting treatment are still not uniform and comparable. Moreover, neither guidelines nor approval by the Food and Drug Administration exist to regulate the use of retinoids in chemoprevention (15).

\section{COX2 Inhibitors, Non-steroid Anti-rheumatics}

COX (cyclooxygenase) inhibitors play a role in the chemoprevention of several types of tumours. Cyclooxygenase-2 (COX-2) and cyclooxygenase-1 (COX-1) as well as lipooxygenase (LOX) are key enzymes in the synthesis of eicosanoids - signalling molecules derived from arachidonic acid. COX-2 is stimulated by oxidative stress, growth factors (EGF) and cytokines IL-6 or TNF. COX-2 is not expressed in healthy breast tissue, but there its over-expression has been described in hyperplasia and carcinoma tissue (16).

Over-expression of COX-2 leads to over-production of eicosanoids. Since it produces prostaglandin E2 (PGE2), COX-2 plays a role in the regulation of estrogen. PGE2 increases the expression of the cytochrome P-450 enzyme complex known as aromatase, which catalyzes androgen to estrogen conversion. COX-2 could be induced by many factors, such as mitogens, cytokines, and hormones (17). Molecular studies suggest that COX-2 is related to mutagenesis, angiogenesis, inhibition of apoptosis and aromatase-catalyzed estrogen biosynthesis. There is also a hypothesis that local estrogen levels induced by elevated 
aromatase activity stimulate tumour growth; thus the development and role of COX-2 seems to be essential in breast cancer. COX-2 is known to be expressed in several cancers, including colorectal, prostate, lung, pancreas, and breast cancer (18).

The effect of NSAIDs (non-steroid anti-inflammatory drugs), which work as selective COX inhibitors, is based on the same principle. There is a huge decrease in the incidence of breast and colorectal carcinoma during chronic intake of NSAID. But longterm usage of some NSAIDs leads to health problems $(19,20)$. In lung carcinoma chemoprevention, several studies have been done with deguelin, giving hopeful results. Deguelin is a rotenoid from the flavonoid group present in legume family plants, and it inhibits COX-2. Additional effects are that it is a strong proapoptotic, via the reduction of anti-apoptotic molecules expression (XIAP - x-linked inhibitor of apoptosis proteins, HSP90 - heat shock proteins), and it has anti-proliferative and anti-angiogenic potency (21). Another member of NSAIDs from flavonoids is quercetin which inhibits the cyclooxygenase pathway. The effect of quercetin-induced apoptosis in neuro2a cells by the activation of intrinsic caspase cascade pathway was assessed by the expression of caspases 3 and 9 , bax, cytochrome-c, which led to the induction of apoptosis (22).

\section{Antiestrogens and Phytoestrogens}

Antiestrogen is a substance that keeps cells from making or using estrogen. Antiestrogens may stop some cancer cells from growing and are used to prevent and treat breast cancer. They are also being studied in the treatment of other types of cancer. The effect of estrogen on other tissues like bone, endometrial or fat is also being studied. An antiestrogen is a type of hormone antagonist. There are differences in mechanism of action within hormonal chemotherapeutics. SERMs (selective estrogen response modifiers), which include therapeutics such as raloxifen, arzoxifen and tamoxifen, decrease breast-tumour incidence in women with a genetic predisposition $(23,24)$. SERM have both estrogen agonist and antagonist actions. The most important anti-cancer effect is estrogen receptors (ER) blocking and elimination of the stimulating effect on mammary gland epithelium proliferation. They inhibit the formation of a tumour by stopping the G1 phase of the cell cycle following the inhibition of $\mathrm{pRb}$ (retinoblastoma protein) and CDK2 (cyklin-dependent kinase 2). SERDs (selective estrogen receptor down regulators) are pure estrogen antagonists and probably decrease the number of ER by degradation after binding (e.g. fulvestrant) (25). Both preclinical and clinical studies show SERDs to have bigger potency when compared with SERMs in breast cancer cells growth inhibition. They are devoid of any estrogen-agonist action on the uterus and vagina but lack the beneficial effects of SERMs on the bone and serum lipid profile $(24,26-28)$.

The last from this group are AIs (aromatase inhibitors). After menopause, most circulating estrogens originate from androgenestrogen conversion by the activity of enzyme aromatase. The development progressed from non-selective to selective non-steroid inhibitors of aromatase, such as letrosol and anastrosol, which block estrogen production (29). The importance of aromatase quantity in tumours was evaluated by Miller et al (31). They observed that most tumours obtain estrogen thanks to both local and peripheral aromatase. If the local aromatisation is crucial for the mammary gland, then in situ blockade of estradiol biosynthesis by aromatase inhibitors is possible and can be effective in mammary gland carcinogenesis suppression. Geisler et al. (32) described the suppression of intratumoural estrogen levels after application of aromatase inhibitors. Mackay et al. (33) described very variable responses after application of aromatase inhibitor YM511, and intratumoural inhibition of aromatase was not sufficient to provide an antiproliferative effect. The expression of the aromatase gene in tumour tissue is controlled by different transcription promoter areas when compared with normal tissue. The importance of chemoprevention or adjuvant hormonal therapy by aromatase inhibition lies in mammary-carcinogenesis inhibition and depression of relapse risk and mortality in patients (34). In comparison with chemotherapy, hormonal therapy had an identical effect considering their relapse risk (35). It is necessary to evaluate the effects of aromatase inhibitors, NSAID and COX2 inhibitors, in terms of effectiveness and toxicity (raloxifen).

Phytoestrogens are bioactive, naturally occurring plant compounds with a structure similar to that of estrogen resulting in the ability to cause estrogenic and/or antiestrogenic effects through binding to estrogen receptors or modulating the concentration of endogenous estrogens via binding or inactivating some enzymes. Plants serving as food sources of phytoestrogens are nuts, oilseeds, legumes, soya, cereals, and many others. Phytoestrogens are part of a plant's defence mechanism (isoflavones, lignans, coumestanes). Isoflavones are the source of the aglycanes genistine, daidzine and glycetine, which are transformed in the body into active forms as genistein, daidzein, glycetein. Daidzein and genistein behave primarily as weak estrogen agonists (bone, brain), but they can also have an anti-estrogen effect (breast, uterus) (Fig. 3. A and B). Genistein inhibits androgen-dependent and androgenindependent prostatic oncocells in vitro and in vivo (36-38).

\section{Polyphenols}

Polyphenols are a group of chemical compounds contained in plants. They are characterised by the presence of large multiples of phenol units. The properties of particular polyphenols depend on the number and characteristics of phenol structures. Polyphenols are generally divided into phenolic acids, stilbenes, lignans, flavonoids, and other unclassified polyphenols. Phenol phytochemicals

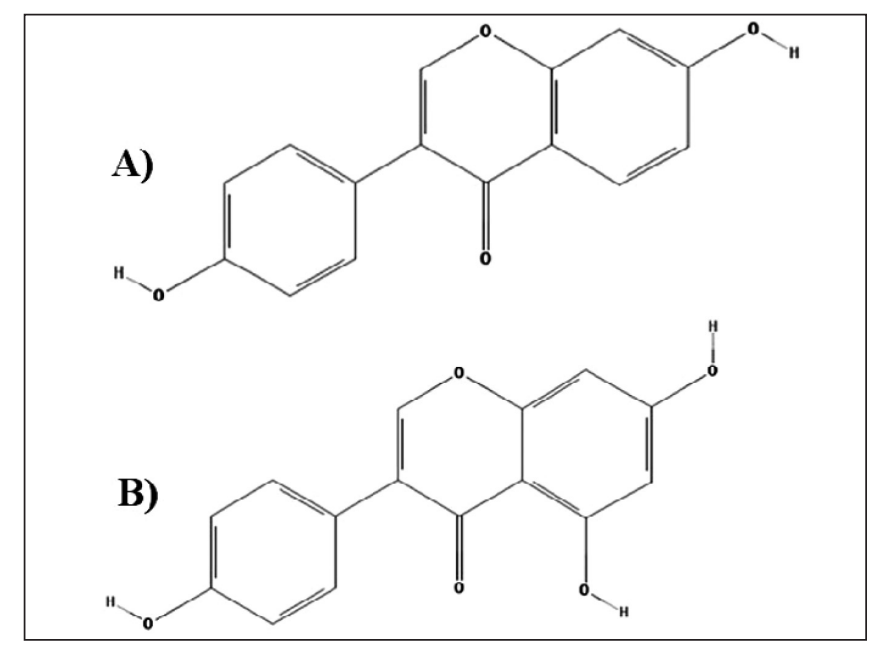

Fig. 3. Phytoestrogens, A) daidzein, B) genistein. 
are present everywhere in the plant kingdom (green tea, berries, wine, olive oil, walnuts, coffee) (39-44). Structures of individual polyphenols are shown in Fig. 4.

\section{Ellagic Acid}

Ellagic acid (Fig.4.A) is a polyphenolic antioxidant present in raspberries, strawberries, cranberries, and many other plant foods. It is a dimer of gallic acid. The anticancer properties of ellagic acid are based on the direct ability to direct the inhibition of the binding of some carcinogens (e.g. nitrosamines, polycyclic aromatic hydrocarbons) to DNA. Like other polyphenolic antioxidants, ellagic acid has in cell models a chemo-protective effect by limiting oxidative stress $(45,46)$.

\section{Caffeic Acid}

Phenol acids and their derivatives show the effects of primary antioxidants. Activity depends on the number hydroxyl groups in the molecule. Antioxidants are generally more active derivatives of cinnamic acid and o-diphenols (e.g. caffeic acid and its ester chlorogenic acid) (47). Caffeic acid is formed from 4-hydroxycinnamic acid and its derivatives, such as caffeic acid phenethyl ester (CAPE), are key intermediates in the biosynthesis of lignins. Caffeic acid (Fig. 4.B) is contained in coffee, potatoes, apples, and pears. It has been shown to inhibit carcinogenesis, although other experiments have revealed possible carcinogenic effects. It is known as an antioxidant in vitro and also in vivo. In addition, caffeic acid shows immunomodulatory and anti-inflammatory activities (48).

\section{Curcumin}

Plant extracts usually have more than one chemopreventive mechanism. It has been experimentally shown that the lightyellow flavonoid present in Curcuma longa roots is able to inhibit initiation, promotion and progression of the cancer genetic process. Curcumin (Fig. 4.C) suppresses and inverts carcinogenesis via multifaceted molecular targets. Experimental studies and experimental models have revealed that curcumin regulates several molecules in the cell-signal transduction pathway, including NF-кB, Akt, MAPK, p53, Nrf2, Notch-1, JAK/STAT, $\beta$-catenin and AMPK. The cell-signalling pathways modulation, through the pleiotropic effects of curcumin, likely activates cell death signals

A)

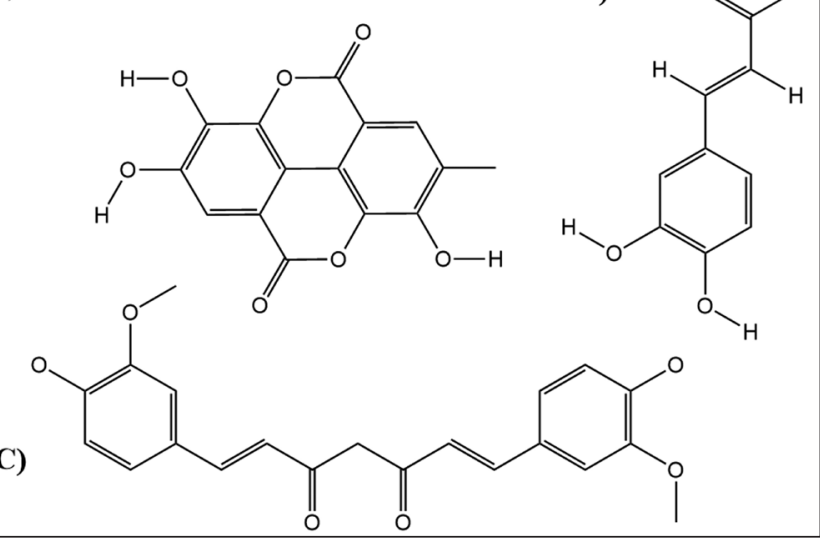

Fig. 4. Polyphenols, A) Ellagic acid, B) Caffeic acid, C) Curcumin. and induces apoptosis in cancer cells, thereby inhibiting disease progression $(49,50)$. Plummer et al. (51) reported the inhibition of $\mathrm{NF}-\mathrm{kB}$ activation by curcumin, leading to the inhibition of COX-2 expression. The COX-2 gene is induced by tumour promoters and tumour necrotic factor alpha (TNF-alpha) in intestine epithelial cells. Curcumin, like another polyphenols, shows significant antitumour synergism when compared with normal cytostatics, e.g. vincristine, gemcitabine or 5-phlourouracil (52).

\section{Ferulic Acid}

In plants, caffeic acid (Fig. 5.A) is transformed into ferulic acid ((E)-3-(4-hydroxy-3-methoxy-phenyl) prop-2-enoic acid). Ferulic acid is usually associated with food and the fibre in it. The main sources of ferulic acid are foods such as wheat bran, but also coffee, apples, artichokes, peanuts, oranges, and pineapples. Animal studies and in vitro studies suggest that ferulic acid may have direct antitumour activity against breast and colon cancer (53-55). Ferulic acid has a significant role in the inhibition of abnormal cell proliferation in cancer cells occurring in induced carcinogenesis due to its modulatory effect on pro-apoptotic genes p53 and bcl-2 expression (56).

\section{Resveratrol}

Resveratrol (3, 5, 4-trihydroxy-trans-stilben) (Fig. 5.B) is a natural phenol and phytoalexin produced by many different plants (e.g. grapevine, currants, juniper, grapefruit) when attacked by pathogens (bacteria, mushrooms). Its antioxidant effects and DNA damage inhibition have been described in many studies. The effects on surviving periods of living organisms are very controversial. In mice and rats, several positive effects were described: e.g. anticancer, anti-inflammatory, glycaemia reduction and different cardiovascular benefits (57-59). Clinical studies on humans are currently taking place. It is assumed that due to its ability to inhibit androgen receptor it has a positive effect on the prevention of prostate cancer $(60,61)$.

\section{Catechins}

The polyphenols present in green tea neutralising $\mathrm{O}_{2}$ radicals (ROS) that are produced endogenous or by chemical carcinogens are currently very popular. Catechins present in green tea (epicatechine-EC, epigalocatechine-EGC, epicatechine gallate-ECG, and epigalocatechine gallate - EGCG) belong to the green tea polyphenol group (Camellia sinensis). Epicatechine (Fig. 5.C) inhibits the formation and progression of oncologic disease. It has a synergic action together with other specific experimental chemopreventive substances and is used in lung and colorectal carcinoma therapy (60-65).

\section{Sulphur-containing compounds \\ Isotiocyanates}

Vegetable foods with typical flavours such as wasabi, horseradish, watercress, mustard, radish, broccoli, cabbage, kale, or Brussels sprouts contain compounds called glucosinolates. When plant cells are destroyed, the glucosinolates released are converted by the enzyme myrosinase (present in plants and also in the bowel) into isothiocyanates. Isothiocyanates such as phenethyl isothiocyanate (PEITC) and sulforaphane are potent inhibitors of hydrolase enzyme CYP2E4, which oxidises compounds such 


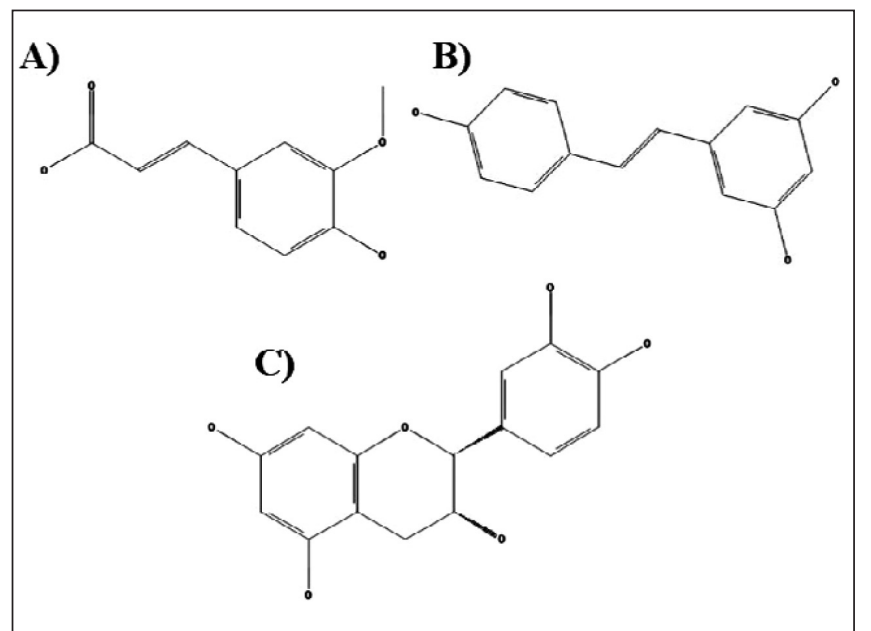

Fig. 5. Other polyphenols, A) Ferulic acid, B) Resveratrol, C) Epicatechine.

as benzo[a]pyrene and other polycyclic aromatic hydrocarbons (PAHs) into more polar epoxy-diols, which can induce mutation and cancer development. By this mechanism isothiocyanates prevent the potential activation of carcinogens (66). They also occur in raspberries, blackberries, licorice, blackberry, cocoa, and tomato. A study by Traka et al. showed that an increased level of dietary sulforaphane is able to modulate gene expression and alternative gene splicing in a PTEN null preclinical murine model of prostate cancer $(67,68)$.

\section{Sulphides}

Allicin, allyl sulphid and allyl mercaptocysteine are strong antioxidants that increase levels of glutathione in different body cells. As an enzyme substrate of glutathione peroxidise, it prevents cell destruction by peroxidase created during metabolism and other ROS reactions.

Diallyl sulphide - DAS present in garlic and onion is a very strong P45O 2E1 (CYP2E1) inhibitor. CYP2E1 is responsible for some carcinogens metabolism. DAS works as a CYP2E1 substrate and is very important in the inhibition of oncological disease prevalence caused by nitrosamines $(69,70)$.

Among other chemopreventive substances which content sulphur and stimulate glutathion-S-transferase, quinon-reductase and UDP-glucuronyl transferase in liver and colon are glutathione, allyl-sulphides and S-allyl-L-cysteine sulphoxide. They have inhibitory effect to carcinogenesis initiation.

\section{Terpenes}

\section{Lycopene}

Lycopene (Fig. 6.A) is a carotene without vitamin A activity and is found in red fruits and vegetables like carrots, watermelons, tomatoes, papayas, etc. The role of lycopene as a decreasing factor of lung, prostatic and colorectal carcinoma as well as cardiovascular disease has been discussed in many studies. Lycopene has positive antioxidant properties, such as positive modulation intercellular communication and hormonal and immune system changes. New evidence is emerging in regard to metabolic pathways mediating the anti-cancer activities of lycopene. In breast oncotic cells, lycopene blocks insulin-like growth factor1, which stimulates division in tumour cells $(71,72)$.

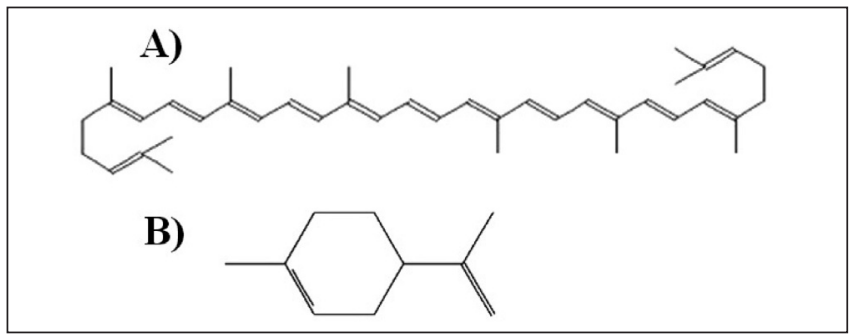

Fig. 6. Terpenes: A) Lycopene, B) Limonene.

\section{Limonene}

D-limonene (Fig. 6.B) is a colourless liquid compound giving a strong smell to citrus fruits. The anticarcinogenic activity of d-limonene has been well documented in the last few years. The anti-arcinogenic activity of d-limonene in $\mathrm{N}$ nitrosodiethylamine (NDEA) induced hepatocarcinogenesis has been reported. The involvement of oncogenes which add to the mechanisms of d-limonene-mediated chemoprevention has also been suggested in the same model system. The over-expression of c-myc oncoprotein in different durations of NDEA-induced hepatocarcinogenesis has been observed and is inhibited completely when d-limonene was treated prior to and along with NDEA (73). D-limonene activated caspase-3 and -9 and PARP cleavage in a dose-dependent manner. Moreover, an increase in Bax protein and cytosol cytochrome c from mitochondria and a decrease in bcl-2 protein were observed following treatment with d-limonene, suggesting that d-limonene induced apoptosis via the mitochondrial death pathway and the suppression of the $\mathrm{PI} 3 \mathrm{~K} /$ Akt pathway (73). D-limonene is recognised as a potential chemotherapeutic agent, however, the details of this mechanism remain unclear (74).

\section{CONCLUSION}

Naturally occurring chemoprotective substances could provide optimal chemoprevention. Many experimental studies daily prove the strong potential of chemopreventive substances regarding the inhibition of progression and formation of metastasis together with their useful properties suitable for oncological therapy. This review described only small portion of the naturally occurring substances with chemopreventive effects, selected according to their efficiencies and healing potential. Research in this field has shown significant progress, because in addition to chemoprevention, natural chemoprotectives have recently been experiencing a huge boom in practical usage, mainly due to their minimal side effects, in place of synthetic drugs. Chemoprevention is one of several promising strategies to reduce the incidence of malignant tumours or help prolong the time of recurrence.

\section{Acknowledgments}

The review was supported by DIAGONKO ITMS:26220220153

\section{Conflict of Interests}

None declared 


\section{REFERENCES}

1. Usera AR, Dolan PM, Kensler TW, Posner GH. Antiproliferative, lowcalcemic, fluorinated sulfone analogs of 1alpha,25-dihydroxyvitamin D3: chemical synthesis and biological evaluation. Bioorg Med Chem. 2007 Aug 15;15(16):5509-18.

2. Usera AR, Dolan P, Kensler TW, Posner GH. Novel alkyl side chain sulfone 1alpha,25-dihydroxyvitamin D3 analogs: a comparison of in vitro antiproliferative activities and in vivo calcemic activities. Bioorg Med Chem. 2009 Aug 1;17(15):5627-31.

3. Gandini S, Francesco FP, Johanson H, Bonanni B, Testori A. Why vitamin D for cancer patients? Ecancermedicalscience. 2009;3:160.

4. Heaney RP, Holick MF. Why the IOM recommendations for vitamin D are deficient. J Bone Miner Res. 2011 Mar;26(3):455-7.

5. Reid IR, Avenell A. Evidence-based policy on dietary calcium and vitamin D. J Bone Miner Res. 2011 Mar;26(3):452-4.

6. Roth DE. Vitamin D supplementation during pregnancy: safety considerations in the design and interpretation of clinical trials. J Perinatol. 2011 Jul;31(7):449-59.

7. Manson JE, Mayne ST, Clinton SK. Vitamin D and prevention of cancer - ready for prime time? N Engl J Med. 2011 Apr 14;364(15):1385-7.

8. Chesney RW. The five paradoxes of vitamin D and the importance of sunscreen protection. Clin Pediatr (Phila). 2012 Sep;51(9):819-27.

9. Connolly RM, Nguyen NK, Sukumar S. Molecular pathways: current role and future directions of the retinoic acid pathway in cancer prevention and treatment. Clin Cancer Res. 2013 Apr 1;19(7):1651-9.

10. Tatebe H, Shimizu M, Shirakami Y, Sakai H, Yasuda Y, Tsurumi H, et al. Acyclic retinoid synergises with valproic acid to inhibit growth in human hepatocellular carcinoma cells. Cancer Lett. 2009 Nov 28;285(2):210-7.

11. Okuno M, Kojima S, Matsushima-Nishiwaki R, Tsurumi H, Muto Y, Friedman SL, et al. Retinoids in cancer chemoprevention. Curr Cancer Drug Targets. 2004 May;4(3):285-98.

12. Hansen LA, Sigman CC, Andreola F, Ross SA, Kelloff GJ, De Luca LM. Retinoids in chemoprevention and differentiation therapy. Carcinogenesis. $2000 \mathrm{Jul} ; 21(7): 1271-9$.

13. Bao GC, Wang JG, Jong A. Increased p21 expression and complex formation with cyclin E/CDK2 in retinoid-induced pre-B lymphoma cell apoptosis. FEBS Lett. 2006 Jun 26;580(15):3687-93.

14. Guidoboni M, Zancai P, Cariati R, Rizzo S, Dal Col J, Pavan A, et al. Retinoic acid inhibits the proliferative response induced by CD40 activation and interleukin-4 in mantle cell lymphoma. Cancer Res. 2005 Jan 15;65(2):587-95.

15. Bettoli V, Zauli S, Virgili A. Retinoids in the chemoprevention of nonmelanoma skin cancers: why, when and how. J Dermatolog Treat. 2013 Jun;24(3):235-7.

16. Lee JA, Bae JW, Woo SU, Kim H, Kim CH. Correlation between COX2 expression and hormone receptors in invasive ductal breast cancer. $\mathrm{J}$ Korean Surg Soc. 2010 Mar;78(3):140-8.

17. Kaneshiro T, Okumura M, Maalouf S, Uflacker A, Maruyama T, Kawamori T. Inhibition of prostaglandin E2 signaling through the EP1 receptor does not affect prostacyclin production in human endothelial cells. Prostaglandins Other Lipid Mediat. 2009 Nov;90(1-2):31-6.

18. Kundu JK, Hwang DM, Lee JC, Chang EJ, Shin YK, Fujii H, et al. Inhibitory effects of oligonol on phorbol ester-induced tumor promotion and COX-2 expression in mouse skin: NF-kappaB and C/EBP as potential targets. Cancer Lett. 2009 Jan 8;273(1):86-97.

19. Srivastava JK, Pandey M, Gupta S. Chamomile, a novel and selective COX-2 inhibitor with anti-inflammatory activity. Life Sci. 2009 Nov 4;85(19-20):663-9.

20. Huls G, Koornstra JJ, Kleibeuker JH. Non-steroidal anti-inflammatory drugs and molecular carcinogenesis of colorectal carcinomas. Lancet. 2003 Jul 19;362(9379):230-2.

21. Davies G, Martin LA, Sacks N, Dowsett M. Cyclooxygenase-2 (COX2), aromatase and breast cancer: a possible role for COX-2 inhibitors in breast cancer chemoprevention. Ann Oncol. 2002 May;13(5):669-78.

22. Sugantha Priya E, Selvakumar K, Bavithra S, Elumalai P, Arunkumar R, Raja Singh P, et al. Anti-cancer activity of quercetin in neuroblastoma: an in vitro approach. Neurol Sci. In press.

23. Boghossian S, Hawash A. Chemoprevention in colorectal cancer - where we stand and what we have learned from twenty year's experience. Surgeon. 2012 Feb;10(1):43-52.

24. Gail MH. The estimation and use of absolute risk for weighing the risks and benefits of selective estrogen receptor modulators for preventing breast cancer. Ann N Y Acad Sci. 2001 Dec;949:286-91.
25. Medina D, Kittrell FS, Hill J, Shepard A, Thordarson G, Brown P. Tamoxifen inhibition of estrogen receptor-alpha-negative mouse mammary tumorigenesis. Cancer Res. 2005 Apr 15;65(8):3493-6.

26. Vermeulen K, Van Bockstaele DR, Berneman ZN. The cell cycle: a review of regulation, deregulation and therapeutic targets in cancer. Cell Prolif. 2003 Jun;36(3):131-49.

27. Lønning PE. Aromatase inhibitors in breast cancer. Endocr Relat Cancer 2004 Jun;11(2):179-89.

28. Stevenson S, Thornton J. Effect of estrogens on skin aging and the potential role of SERMs. Clin Interv Aging. 2007;2(3):283-97.

29. Elkak AE, Mokbel K. Pure antiestrogens and breast cancer. Curr Med Res Opin. 2001;17(4):282-9

30. Geisler J, Detre S, Berntsen H, Ottestad L, Lindtjørn B, Dowsett M, et al. Influence of neoadjuvant anastrozole (Arimidex) on intratumoral estrogen levels and proliferation markers in patients with locally advanced breast cancer. Clin Cancer Res. 2001 May;7(5):1230-6.

31. Miller WR, Bartlett J, Brodie AMH, Brueggemeier RW, di Salle E, Lønning PE, et al. Aromatase inhibitors: are there differences between steroidal and nonsteroidal aromatase inhibitors and do they matter? Oncologist. 2008 Aug;13(8):829-37.

32. Geisler J, Helle H, Ekse D, Duong NK, Evans DB, Nordbø Y, et al. Letrozole is superior to anastrozole in suppressing breast cancer tissue and plasma estrogen levels. Clin Cancer Res. 2008 Oct 1;14(19):6330-5.

33. Mackay A, Urruticoechea A, Dixon JM, Dexter T, Fenwick K, Ashworth A, et al. Molecular response to aromatase inhibitor treatment in primary breast cancer. Breast Cancer Res. 2007;9(3):R37.

34. Bulun SE, Lin Z, Imir G, Amin S, Demura M, Yilmaz B, et al. Regulation of aromatase expression in estrogen-responsive breast and uterine disease: from bench to treatment. Pharmacol Rev. 2005 Sep;57(3):359-83.

35. Sun SY, Hail N Jr, Lotan R. Apoptosis as a novel target for cancer chemoprevention. J Natl Cancer Inst. 2004 May 5;96(9):662-72.

36. Khan AQ, Khan R, Rehman MU, LateefA, Tahir M, Ali F, et al. Soy isoflavones (daidzein \& genistein) inhibit 12-O-tetradecanoylphorbol-13-acetate (TPA)-induced cutaneous inflammation via modulation of COX-2 and NF- $\kappa B$ in Swiss albino mice. Toxicology. 2012 Dec 16;302(2-3):266-74.

37. Liu MM, Huang Y, Wang J. Developing phytoestrogens for breast cancer prevention. Anticancer Agents Med Chem. 2012 Dec;12(10):1306-13.

38. Constantinou AI, White BE, Tonetti D, Yang Y, Liang W, Li W, et al. The soy isoflavone daidzein improves the capacity of tamoxifen to prevent mammary tumours. Eur J Cancer. 2005 Mar;41(4):647-54.

39. Shen MM, Abate-Shen C. Molecular genetics of prostate cancer: new prospects for old challenges. Genes Dev. 2010 Sep 15;24(18):1967-2000.

40. Schmitz-Dräger BJ, Lümmen G, Bismarck E, Fischer C. Prevention strategies for prostate cancer. Minerva Urol Nefrol. 2012 Dec;64(4):225-31.

41. Lee JH, Khor TO, Shu L, Su ZY, Fuentes F, Kong AN. Dietary phytochemicals and cancer prevention: Nrf2 signaling, epigenetics, and cell death mechanisms in blocking cancer initiation and progression. Pharmacol Ther. 2013 Feb;137(2):153-71.

42. Miller PE, Snyder DC. Phytochemicals and cancer risk: a review of the epidemiological evidence. Nutr Clin Pract. 2012 Oct;27(5):599-612.

43. Davalli P, Rizzi F, Caporali A, Pellacani D, Davoli S, Bettuzzi S, et al. Anticancer activity of green tea polyphenols in prostate gland. Oxid Med Cell Longev. 2012;2012:984219.

44. Paluszczak J, Krajka-Kuźniak V, Baer-Dubowska W. The effect of dietary polyphenols on the epigenetic regulation of gene expression in MCF7 breast cancer cells. Toxicol Lett. 2010 Feb 1;192(2):119-25.

45. Vadhanam MV, Ravoori S, Aqil F, Gupta RC. Chemoprevention of mammary carcinogenesis by sustained systemic delivery of ellagic acid. Eur J Cancer Prev. 2011 Nov;20(6):484-91.

46. Umesalma S, Sudhandiran G. Ellagic acid prevents rat colon carcinogenesis induced by 1, 2 dimethyl hydrazine through inhibition of AKT-phosphoinositide-3 kinase pathway. Eur J Pharmacol. 2011 Jun 25;660(2-3):249-58.

47. D'Archivio M, Filesi C, Di Benedetto R, Gargiulo R, Giovannini C, Masella R. Polyphenols, dietary sources and bioavailability. Ann Ist Super Sanita. 2007;43(4):348-61.

48. Dai J, Mumper RJ. Plant phenolics: extraction, analysis and their antioxidant and anticancer properties. Molecules. 2010 Oct;15(10):7313-52.

49. Shehzad A, Lee YS. Molecular mechanisms of curcumin action: signal transduction. Biofactors. 2013 Jan-Feb;39(1):27-36.

50. Alexandrow MG, Song LJ, Altiok S, Gray J, Haura EB, Kumar NB. Curcumin: a novel Stat 3 pathway inhibitor for chemoprevention of lung cancer. Eur J Cancer Prev. 2012 Sep;21(5):407-12.

51. Plummer SM, Hill KA, Festing MF, Steward WP, Gescher AJ, Sharma RA. Clinical development of leukocyte cyclooxygenase 2 activity as a 
systemic biomarker for cancer chemopreventive agents. Cancer Epidemiol Biomarkers Prev. 2001 Dec;10(12):1295-9.

52. Teiten MH, Gaascht F, Eifes S, Dicato M, Diederich M. Chemopreventive potential of curcumin in prostate cancer. Genes Nutr. 2010 Mar;5(1):6174.

53. Han BS, Park CB, Takasuka N, Naito A, Sekine K, Nomura E, et al. A ferulic acid derivative, ethyl 3-(4'-geranyloxy-3-methoxyphenyl)2-propenoate, as a new candidate chemopreventive agent for colon carcinogenesis in the rat. Jpn J Cancer Res. 2001 Apr;92(4):404-9.

54. van der Logt EM, Roelofs HM, Nagengast FM, Peters WH. Induction of rat hepatic and intestinal UDP-glucuronosyltransferases by naturally occurring dietary anticarcinogens. Carcinogenesis. 2003 Oct;24(10):1651-6.

55. Serafim TL, Carvalho FS, Marques MP, Calheiros R, Silva T, Garrido J, et al. Lipophilic caffeic and ferulic acid derivatives presenting cytotoxicity against human breast cancer cells. Chem Res Toxicol. 2011 May 16;24(5):763-74

56. Balakrishnan S, Manoharan S, Alias LM, Nirmal MR. Effect of curcumin and ferulic acid on modulation of expression pattern of p53 and bcl-2 proteins in 7,12-dimethylbenz[a]anthracene-induced hamster buccal pouch carcinogenesis. Indian J Biochem Biophys. 2010 Feb;47(1):7-12

57. Bergman M, Levin GS, Bessler H, Djaldetti M, Salman H. Resveratrol affects the cross talk between immune and colon cancer cells. Biomed Pharmacother. 2013 Feb;67(1):43-7.

58. Wang H, Zhang H, Tang L, Chen $\mathrm{H}$, Wu C, Zhao M, et al. Resveratrol inhibits TGF- $\beta 1$-induced epithelial-to-mesenchymal transition and suppresses lung cancer invasion and metastasis. Toxicology. 2013 Jan 7;303:139-46.

59. Maccario C, Savio M, Ferraro D, Bianchi L, Pizzala R, Pretali L, et al. The resveratrol analog 4,4'-dihydroxy-trans-stilbene suppresses transformation in normal mouse fibroblasts and inhibits proliferation and invasion of human breast cancer cells. Carcinogenesis. 2012 Nov;33(11):2172-80

60. Klink JC, Tewari AK, Masko EM, Antonelli J, Febbo PG, Cohen P, et al. Resveratrol worsens survival in SCID mice with prostate cancer xenografts in a cell-line specific manner, through paradoxical effects on oncogenic pathways. Prostate. 2013 May;73(7):754-62.

61. Fang Y, DeMarco VG, Nicholl MB. Resveratrol enhances radiation sensitivity in prostate cancer by inhibiting cell proliferation and promoting cell senescence and apoptosis. Cancer Sci. 2012 Jun;103(6):1090-8.

62. Mao JT, Nie WX, Tsu IH, Jin YS, Rao JY, Lu QY, et al. White tea extract induces apoptosis in non-small cell lung cancer cells: the role of peroxisome proliferator-activated receptor-\{gamma $\}$ and 15-lipoxygenases. Cancer Prev Res (Phila). 2010 Sep;3(9):1132-40.

63. Saha A, Kuzuhara T, Echigo N, Suganuma M, Fujiki H. New role of (-)-epicatechin in enhancing the induction of growth inhibition and ap- optosis in human lung cancer cells by curcumin. Cancer Prev Res (Phila). 2010 Aug;3(8):953-62.

64. Milligan SA, Burke P, Coleman DT, Bigelow RL, Steffan JJ, Carroll JL, et al. The green tea polyphenol EGCG potentiates the antiproliferative activity of c-Met and epidermal growth factor receptor inhibitors in nonsmall cell lung cancer cells. Clin Cancer Res. 2009 Aug 1;15(15):4885-94.

65. Inaba H, Nagaoka Y, Kushima Y, Kumagai A, Matsumoto Y, Sakaguch $\mathrm{M}$, et al. Comparative examination of anti-proliferative activities of (-)-epigallocatechin gallate and (-)-epigallocatechin against HCT116 colorectal carcinoma cells. Biol Pharm Bull. 2008 Jan;31(1):79-84.

66. Singh SV, Singh K. Cancer chemoprevention with dietary isothiocyanates mature for clinical translational research. Carcinogenesis. 2012 Oct:33(10):1833-42.

67. Traka MH, Spinks CA, Doleman JF, Melchini A, Ball RY, Mills RD, et al. The dietary isothiocyanate sulforaphane modulates gene expression and alternative gene splicing in a PTEN null preclinical murine model of prostate cancer. Mol Cancer. 2010 Jul 13;9:189.

68. Singh SV, Kim SH, Sehrawat A, Arlotti JA, Hahm ER, Sakao K, et al. Biomarkers of phenethyl isothiocyanate-mediated mammary cancer chemoprevention in a clinically relevant mouse model. J Natl Cancer Inst. 2012 Aug 22;104(16):1228-39.

69. Lii CK, Tsai CW, Wu CC. Garlic allyl sulfides display differential modulation of rat cytochrome P450 2B1 and the placental form glutathione S-transferase in various organs. J Agric Food Chem. 2006 Jul 12;54(14):5191-6.

70. Chun HS, Kim HJ, Choi EH. Modulation of cytochrome P4501-mediated bioactivation of benzo[a]pyrene by volatile allyl sulfides in human hepatoma cells. Biosci Biotechnol Biochem. 2001 Oct;65(10):2205-12.

71. Aydemir G, Kasiri Y, Birta E, Béke G, Garcia AL, Bartók EM, et al Lycopene-derived bioactive retinoic acid receptors/retinoid-X receptorsactivating metabolites may be relevant for lycopene's anti-cancer potential. Mol Nutr Food Res. 2013 May;57(5):739-47.

72. Takahashi S, Sato S, Shirai T. Chemoprevention of prostate cancer. Nihon Rinsho. 2011 Jun;69 Suppl 5:56-60. (In Japanese.)

73. Parija T, Das BR. Involvement of YY1 and its correlation with c-myc in NDEA induced hepatocarcinogenesis, its prevention by d-limonene. Mol Biol Rep. 2003Mar;30(1):41-6.

74. Jia SS, Xi GP, Zhang M, Chen YB, Lei B, Dong XS, et al. Induction of apoptosis by D-limonene is mediated by inactivation of Akt in LS174T human colon cancer cells. Oncol Rep. 2013 Jan;29(1):349-54.

Received March 5, 2013

Accepted in revised form July 15, 2013 